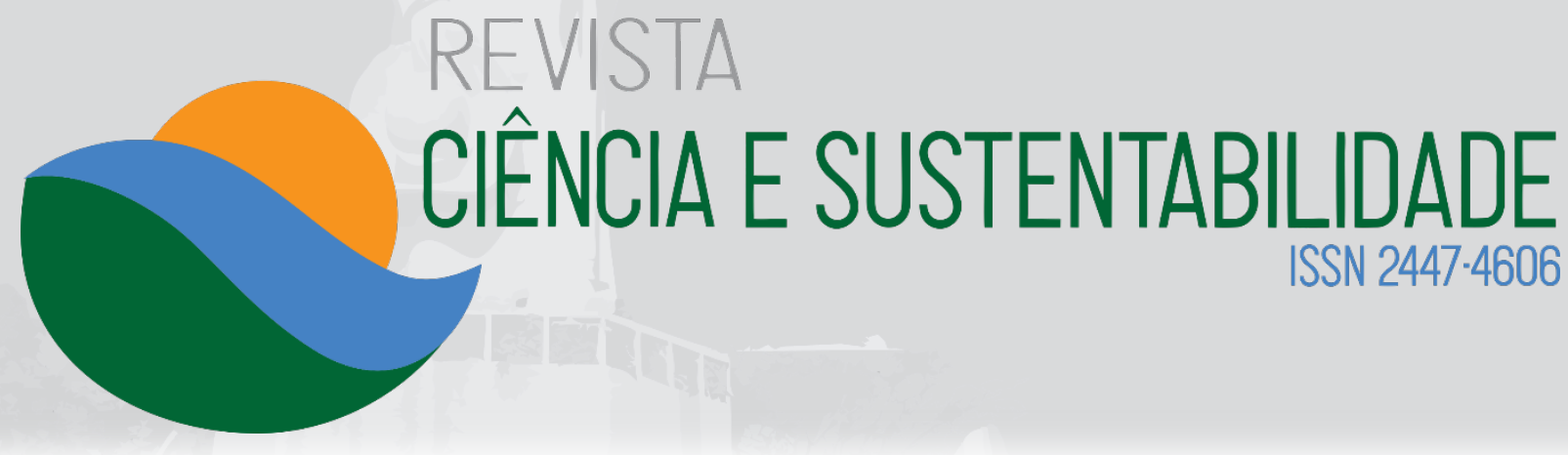

\title{
Os Caminhos das Políticas Públicas de Interiorização da Educação Superior na Macrorregião do Cariri
}

\author{
The Pathways of the Public Policies of Interiorization of Higher Education in \\ the Cariri Macroregion
}

Calebe Lucas Feitosa Campelo Universidade Regional do Cariri (URCA) Atualmente é estudante do Curso de Ciências Biológicas da Universidade Regional do Cariri-URCA (Brasil), Professor da rede pública e privada de ensino no ensino fundamental II e médio. campelocalebe@gmail.com

\section{Maria Lúcia Ferreira da Silva Universidade Vale do Acaraú-UVA Possui graduação em Administração de Empresas pela Universidade Estadual Vale do Acaraú (2008). Especialista em Gestão Hospitalar e Sistemas de Saúde pela Universidade Regional do Cariri Especialista em Engenharia de Segurança do Trabalho pela Faculdade Leão Sampaio Especialista em Docência do Ensino Superior pela Faculdade Católica do Cariri marluci.fs@hotmail.com}

\section{Marcos Ítalo Vitorino Pereira} Centro Universitário Leão Sampaio (UNILEÃO)

Possui graduação em Psicologia pela Faculdade Leão Sampaio (2015). Pósgraduando em Psicoterapia Analítico

\begin{abstract}
Resumo
Desde os anos 2000, na região do Cariri, há maior intensificação e diversificação das atividades socioeconômicas. Isso atribui novos contornos e configurações à região. A forte presença de instituições de ensino superior também é sentida nesse período. Nesse viés, o presente estudo tem o objetivo de analisar de forma crítica o fenômeno de interiorização da Educação Superior na macrorregião Caririense, que vem passando por um processo vertiginoso nos setores educacionais e econômicos. Para a presente abordagem, foi feito um recorte dimensional dos anos 2000 até 2015. Para isto foi realizada uma pesquisa bibliográfica documental, tendo como baliza estudos que tratam da expansão do ensino superior brasileiro e para a sistematização do estudo foi utilizada uma abordagem quantitativa a qual buscou como referência o censo do ensino superior brasileiro colhido e documentado a partir do Instituto Nacional de Estudos e Pesquisas (INEP), bem como o último Censo Demográfico do Instituto Brasileiro de Geografia e Estatística (IBGE). Com efeito, o trabalho apresenta um panorama dos contributos que as políticas públicas deram para a interiorização do Ensino Superior no Cariri, assim
\end{abstract}


Comportamental pela Centro Universitário Dr. Leão Sampaio, Pós-graduando em Docência do Ensino superior pela FATECE.

italovitorinop@gmail.com

\section{Mateus Pereira Santana}

Universidade Regional do Cariri (URCA) mateuspereirasantana@hotmail.com como os impactos para o desenvolvimento regional e formação de um dos maiores polos universitários do interior do Ceará. Com efeito, a pesquisa ainda aponta os entraves que ainda existem para a democratização da Educação Superior, não somente no Cariri, mas ao nível nacional. As análises realizadas nas discussões da pesquisa demonstram o contraste que foi criado entre o discurso de democratização da Educação Superior e o que foi efetivado na prática, demonstrando os resultados da parceria público-privada iniciado nos governos de Fernando Henrique Cardoso e continuados pelos governos posteriores com reformas e parcerias realizadas, sem contudo conseguir garantir educação pública ao nível de ensino superior gratuita a toda a população, sendo fundamental a reformulação e consequente análise das políticas públicas aplicadas.

Palavras-chave: Políticas públicas. Educação superior. Crajubar. Desenvolvimento Regional.

\section{Abstract}

Since the 2000s, in the Cariri region, there has been a greater intensification and diversification of socioeconomic activities. This assigns new contours and settings to the region. The strong presence of higher education institutions is also felt during this period. In this bias, the present study aims to critically analyze the phenomenon of interiorization of Higher Education in the macro-region of Cariri, a region that has undergone a process of high educational and economic growth, performing a dimensional cut from the years 2000 to 2015 . For this was done a bibliographical-documentary research, having as a beacon scholars that deal with the expansion of Brazilian higher education and for the systematization of the study was used a qualitativequantitative approach which sought as reference the census of Brazilian higher education collected and documented from of the National Institute of Studies and Research (INEP), as well as the last demographic census of the Brazilian Institute of 
Geography and Statistics (IBGE). In fact, the work presents an overview of the contributions that public policies gave to the internalization of as well as the impacts on regional In fact, the research still points to the obstacles that still exist for the democratization of Higher Education, not only in Cariri, but at the national level. The analyzes carried out in the research discussions demonstrate the contrast between the discourse on the democratization of Higher Education and what was done in practice, demonstrating the results of the public-private partnership initiated in the governments of Fernando Henrique Cardoso and continued by the subsequent governments that with the reforms and partnerships they have not been able to guarantee free public education at the level of free education for all the population, being fundamental the reformulation and consequent analysis of the public policies applied.

Keywords: Public policies. College education.

Crajubar. Regional development. 


\section{INTRODUÇÃO}

A Educação Superior no Brasil começa de uma forma tardia, com o objetivo de promover e beneficiar a elite brasileira. Fato, que a economia do Brasil colonial era substanciada na economia agrária, baseada no latifúndio, no trabalho escravo e na monocultura, voltada para as exportações com a finalidade de fornecer subsídios à economia internacional.

No delinear da história, o panorama da educação superior não se modificou do seu aspecto inicialmente elitista, mas se modificou enquanto sua natureza e seu modelo. As políticas se voltaram as condicionantes do mercado aplicando as reformas econômicas que fortaleceram as parcerias públicas-privadas e sua relação com o mercado mundial (MACEDO et al, 2016).

No Brasil, a implantação da economia neoliberal foi marcada na década de 1990 e segue até os dias atuais. Alguns marcos são necessários para delimitar e identificar a maturação do ensino superior no Brasil. A começar Sguissardi (2004) aponta como marcos históricos a partir do Plano Diretor da Reforma do Estado (1995), da Legislação sobre os fundos setoriais e do conjunto de decretos, da Lei de Diretrizes e Bases da Educação — LDB (Lei 9.394/96), da Lei das Fundações (Lei 8.958/94), decretos, portarias, PEC's, Projetos de Lei (da Autonomia, da Inovação Tecnológica, etc.) que modificaram as relações da Universidade, Sociedade e Estado.

Sob essa égide, é de fundamental importância analisar a política de educação superior no Brasil, que no início dos governos petistas em 2003, passou pelo processo de interiorização, ou seja, uma descentralização das capitais para o interior dos estados.

Destacam-se algumas indagações pertinentes que não serão respondidas nessa pesquisa, mas que servem para pesquisas posteriores. Que natureza teve essa interiorização das universidades? Teve qualidade? Financiamento correspondente? Houve concurso para atender a demanda? A política de permanência estudantil funciona?

Nesse contexto, o presente artigo tem como finalidade analisar a interiorização do ensino superior no Ceará no período dos anos 2000 até 2015, mais especificamente na macrorregião do Cariri. Região de destaque tanto pela economia pulsante como pela forte matriz cultural as cidades de Crato, Juazeiro do Norte e Barbalha, que compõem o triângulo Crajubar são as principais no quesito expansão do ensino superior. Essa 
localidade foi selecionada em decorrência da sua densidade populacional e de suas receitas, que serviram de atrativo para a interiorização do ensino superior nessa região e consequentemente o desenvolvimento regional.

$\mathrm{Na}$ referida região é encontrada o Geopark Araripe, o único geoparque da América do Sul, onde sua sede fica na cidade do Crato. Nesse contexto, afere-se o atrativo do turismo na região, trazendo pessoas de diferentes contextos sociais, regiões e de países diferentes. O geoturismo na região tem um forte potencial de geração de empregos diretos e indiretos na comunidade que ligados ao desenvolvimento e expansão da Educação Superior fortalece a qualificação laboral, o que favorece a migração de grandes indústrias como é o caso da indústria Grendene localizada na cidade do Crato, considerada uma das maiores indústrias de calçados do país, atualmente emprega em seu polo cratense mais de 2.000 colaboradores.

Assim, surgem alguns questionamentos sobre a interiorização do ensino superior no Cariri que serão o foco da presente pesquisa. Qual a natureza das Instituições de Ensino Superior (IES) no Cariri? Qual o nível de escolaridade na região do Crajubar? Que setor(es) foram beneficiados com o fenômeno da interiorização?

É notório que o nível de escolaridade de uma população traz diversas melhorias, que deve andar a parri passu com o desenvolvimento regional. São fatores fundamentais para o combate ao desemprego estrutural, no atual período onde se exige da população um nível de escolaridade cada vez mais elevado.

Para a metodologia foi realizada uma pesquisa bibliográfica-documental, com aporte teórico em Marilena Chauí (1999), Valdemar Sguisardi (2004), Roberto Leher (2016), dentre outros teóricos que estudam a expansão do ensino superior. Também foram coletados dados do Instituto Nacional de Estudos e Pesquisas Educacionais Anísio Teixeira (INEP) dos anos 2000 a 2015, do Instituto Brasileiro de Geografia e Estatística (IBGE) e do Censo Demográfico (2010).

Assim, será feita uma análise crítica sobre a expansão e o fenômeno da interiorização do ensino superior no Cariri verificando os impactos das políticas educacionais implementadas nos governos Fernando Henrique Cardoso (1995-2003), Luiz Inácio Lula da Silva (2003-2011), Dilma Vana Rousseff (2011- 2016) e início do governo Michel Temer (2016-2018). 


\section{A MÃO INVISÍVEL: A MERCANTILIZAÇÃO DA EDUCAÇÃO}

Em tempos de crise do capitalismo, a retirada de direitos sociais dos trabalhadores se faz necessária para manter a classe dominante no poder, sendo os detentores do conhecimento. Para tal feito, as contrarreformas do Estado são o principal objeto, já que o Estado é utilizado como poder extra econômico.

Consoante, a reforma do Estado como ferramenta de fuga da crise do capitalismo carrega seu pressuposto ideológico que deve ser analisado de acordo com o contexto político e econômico em que o país perpassa.

Krawczyk (2005) destaca as mudanças em que o conceito de educação na América Latina e mais especificamente no Brasil foram sendo elaboradas e absorvidas. Inicialmente com a Constituição de 1988 a educação promulgava-se como dever do Estado. Já quando elaborada a LDB em 1996, foram deixadas brechas para interpretar a educação como um serviço; portanto passível de negociações e oferecida livremente pelo mercado. É com base nesse entendimento que grupos empresariais estrangeiros e nacionais investem no setor educacional com vistas numa atividade meramente lucrativa, muitas vezes sem o compromisso social.

A Reforma do Estado tem um pressuposto ideológico básico: o mercado é portador de racionalidade política e agente principal do bem-estar da República. Esse pressuposto leva a colocar direitos sociais (como a saúde, a educação e a cultura) no setor de serviços definidos pelo mercado (CHAUÍ, 1999).

Nessa linha de raciocínio, está incutido as ideias advindas do neoliberalismo, que estão bem sintetizadas na obra de Hayek, O Caminho da Servidão, publicada em 1944, que aglutinava as ideias econômicas de Karl Popper, Ludwing von Mises e da Milton e Beth Friedman, o pensamento girava em torno da reforma do Estado, no intuito de preconizar o Estado de Bem-Estar social europeu (SAMPAIO et al, 2002).

As sementes do pensamento neoliberal são dispersadas em 1989, em uma reunião promovida pelo Institute from International Economics com o tema: "Latin American Adjustment: How much has happened?" onde economistas e cientistas políticos neoliberais juntamente com o Banco Mundial, BID, FMI dentre outros autores importantes da América Latina elaboraram em Washington um documento oficial intitulado "Consenso de Washington" que regimentava os dogmas do neoliberalismo a saber: disciplina fiscal; regime cambial; reforma tributária; liberalização financeira; 
priorização dos gastos públicos; liberalização comercial; privatização; desregulação e propriedade intelectual e investimento direto estrangeiro (BATISTA, 1994).

É sob o regimento dessas ideias que o neoliberalismo se difunde na América Latina. Ressalta-se que no neoliberalismo surgem algumas palavras como forma de redirecionar as reais metas do neoliberalismo, ou melhor explicitando Ressemantização, conceitos antes utilizados pela esquerda ou por correntes democráticas agora são usados pelas agências multilaterais (LIMA et al, 2011).

Concomitantemente, Chauí (1999) destaca alguns termos utilizados como "qualidade universitária", "avaliação universitária" e "flexibilização" da universidade. Para desvendar os conceitos, a autora supracitada define que a autonomia significa, o gerenciamento empresarial da instituição, assim, é deixado brechas para a universidade "captar recursos", com a parceria público-privada. A "flexibilização" se torna via de regra do corolário da "autonomia", nessa parceria a universidade deixa de ser uma instituição e passa a ser uma organização. entende- se que a instituição tem a sociedade como sua referência e princípio, já a organização difere da instituição pelas suas práticas sociais que está referenciada em um conjunto particular de interesses e objetivos.

Nessa lógica, é possível verificar a captação da educação pelo mercado. O marco se inicia no governo FHC (1995-2003), com sua atilada estratégia política, quando sanciona os decretos 2.207/97, 2.306/97 e 3.860/01 causando discrepância no entendimento da letra, mas não do espírito que tem como objetivo "ressignificar" o Artigo 207 da Constituição Federal dissociando o tripé do ensino, pesquisa e extensão da universidade, quando por esses decretos retira da obrigatoriedade essas três ações, afastando qualquer imposição legal para a criação de novas IES, e por esses decretos é nítida a "flexibilização" para a captura da educação pelo mercado (SGUISSARDI, 2004).

Em continuidade, mudam-se os atores, mas a peça continua a mesma com a mudança para o governo Luiz Inácio Lula da Silva (2003-2007) que encontrou um país com o nível de escolaridade baixo, e começou a implementar reformas no ensino superior com um plano de educação alinhado ao mercado, causando divergência no discurso democrático sobre educação. O mosaico é exposto pelo movimento Todos pela Educação que agrega diversos setores financeiros, a priori tendo como carro chefe o holding Itaú- Unibanco, pelo Bradesco, pelo Santander, dentre outras 
organizações empresariais e seus derivados e meios de comunicação como Roberto Marinho, Victor Civita, e pelo Terceiro Setor, como Airton Senna e Itaú Cultural, o setor de commodities também pegam a fatia do bolo, como a Gerdau e Vale juntamente com outras grandes corporações que utilizam suas ações em educação no mercado flutuante (LEHER, 2016).

Ainda no governo Lula da Silva (2003-2011) o seu projeto educacional recebe o nome da coalizão empresarial: Plano de Desenvolvimento da Educação: compromisso Todos pela Educação, seguindo, via de regra, as orientações das agências multilaterais como o Fundo Monetário Internacional, Banco Mundial, dentre outras que influenciaram as mudanças no ensino superior também nos países centrais, a ser observado pelo Processo de Bolonha, os moldes do Projeto Tunning de competências mundiais, a adoção do modelo das competências mundiais, a expansão dos cursos tecnológicos com formação aligeirada referenciados nos commuty colleges balizaram as reformas educacionais do governo Lula (LEHER, 2016).

Com as orientações das agências multilaterais, os governos sucessores ao FHC e Lula da Silva, seguiram as mesmas políticas, a única diferença foi a forma, contudo a ideologia, bem como o conteúdo seguiram os mesmos. Mancebo et al (2016) destaca que no governo Dilma Rousseff, a contrarreforma do Estado continuou por meio de emendas parlamentares, Decretos, PEC's, mudanças nos currículos, nas avaliações, na precarização do trabalho docente e na emergência da mudança institucional para promoção da expansão da educação superior por meio do programa de apoio ao Plano de Reestruturação e Expansão das Universidades Federais (REUNI), o fortalecimento da Universidade Aberta do Brasil (UAB), com os cursos à distância e a proliferação de cursos de nível técnicos.

Nos governos petistas, o lobby privatista não deixou de crescer e se organizar sobre a captação da educação. Programas como o PROUNI e FIES, trouxeram grande rentabilidade para o setor financeiro. Com a isenção fiscal o PROUNI que apareceu envolto no discurso de incluir a classe trabalhadora dentro da educação superior, beneficiou as instituições privadas. Os recursos que o Estado deixou de arrecadar mediante a isenção fiscal foram: Contribuição Social sobre o lucro líquido (CSLL), Contribuição Social para o Financiamento da Seguridade Social (COFINS) e da contribuição para o Programa de Integração Social (PIS) e do Imposto de Renda das Pessoas Jurídicas (IRPJ) (LIMA et al, 2011). 
Nesse delinear, o PROUNI foi um dos exemplos de uma política focalizada, sendo que para facilitar por meios legais a expansão, foi sancionado pelo Decreto $\mathrm{n}^{\circ}$ 2.306/97, a desfiguração do modelo universitário, considerado oneroso e improdutivo, permitiu a diferenciação das IES em: Universidades; Centros Universitários; Faculdades Integradas; Institutos Superiores ou Escolas Superiores, por meio de medidas tácitas como essa, é possível desvendar a não neutralidade do Estado, e observar a quem de fato ele serve e de que lado o Estado está, e esse lado não é dos trabalhadores, mas sim dos grandes empresários (LIMA et al, 2011).

\section{EXPANÇÃO DO ENSINO SUPERIOR NO CARIRI}

A macrorregião do Cariri, em especial o triângulo Crajubar, formado pelas três cidades: Crato, Juazeiro do Norte e Barbalha tem se desenvolvido regionalmente em níveis que impressionam e tem apresentado nos últimos anos como um campo promissor para investimentos em diversos setores.

Concomitantemente, a região do Crajubar se tornou um polo universitário, já que cada vez mais o mercado de trabalho exige mão de obra gradativamente qualificada. Nessa lógica, a educação tem se transformado num mercado para atender a uma clientela específica e cada vez mais exigente. O setor da educação superior tem sofrido grandes mudanças nos últimos anos, em decorrência das crises cíclicas do capitalismo, que necessita cada vez mais mudar de vestes e de nomes.

Nesse sentido, Chaui (1999) constata que ocorreu uma passagem da condição da universidade ser uma instituição para ser uma organização e assim foi adquirindo novos modelos. A universidade clássica era voltada para o conhecimento e para sanar as necessidades da sociedade, já a universidade funcional estava voltada para o mercado de trabalho, e por fim, a nova universidade operacional que não é mais uma instituição, mas sim uma organização está voltada para ela mesma, vinculada a lógica do gerenciamento e da arbitragem dos contratos (CHAUI, 1999).

Sob essa classificação elucidada que nossa análise irá se debruçar. Nessa seção, iremos fazer uma análise sobre o nível de escolaridade na região do Crajubar, assim como analisar a natureza da educação superior nesse território. 
A tabela número 01 mostra o número de pessoas que cursaram a educação superior em instituições privadas e públicas no Crajubar no ano de 2010 de acordo com o último censo.

Tabela 01 - Níveis de escolaridade em instituições públicas e privadas no triângulo

\begin{tabular}{|c|c|c|c|c|}
\hline & & Crato & Juazeiro & Barbalha \\
\hline \multirow{2}{*}{ Graduação } & Pública & $\begin{array}{l}2.970 \\
(59 \%)\end{array}$ & $\begin{array}{l}3.368 \\
(38 \%)\end{array}$ & $885(45 \%)$ \\
\hline & Particular & $\begin{array}{l}2.103 \\
(41 \%)\end{array}$ & $\begin{array}{l}5.341 \\
(62 \%)\end{array}$ & $1.062(55 \%)$ \\
\hline \multirow{2}{*}{ Especialização } & Pública & $558(78 \%)$ & $180(24 \%)$ & 0 \\
\hline & Particular & $160(22 \%)$ & $572(76 \%)$ & $56(100 \%)$ \\
\hline \multirow{2}{*}{ Mestrado } & Pública & $66(52 \%)$ & $62(67 \%)$ & $9(19 \%)$ \\
\hline & Particular & $60(48 \%)$ & $30(33 \%)$ & $39(81 \%)$ \\
\hline \multirow{2}{*}{ Doutorado } & Pública & $38(100 \%)$ & $26(55 \%)$ & 0 \\
\hline & Particular & 0 & $14(35 \%)$ & 0 \\
\hline
\end{tabular}

Fonte: IBGE (2010).

Pela análise dos dados é possível identificar que em sua maioria, as pessoas da macrorregião do Cariri que chegaram ao ensino superior se graduaram no ensino privado com o número de 8.506 em contrapartida do ensino público que foi na cota de 7.222 , ou seja, uma diferença de 1.283 pessoas. Se for considerado que a educação é um dever do Estado e que todos devem ter acesso, teremos na realidade 9.789 que não utilizaram o ensino público, umas das questões que se pode aferir é a falta de vagas e a pouca variedade de cursos no Ensino Público.

Observa-se que na cidade do Crato a maioria das pessoas que frequentaram alguma modalidade do ensino superior graduou-se em instituição pública. Esses números podem ser explicados por decorrência de 3 instituições públicas: a Universidade Federal do Cariri-UFCA, Instituto Federal de Educação, Ciências e Tecnologia do Ceará- IFCE e a Universidade Regional do Cariri-URCA, possuírem o seu campus sede na referida cidade. Porém, se observarmos a diferença no número de pessoas distribuídas entre as modalidades, notar-se-á também um avanço do ensino privado na referida cidade que poderá ser explicado pela facilidade de acesso 
a estas instituições. Já que não se explica o fato de se preferir um ensino superior pago em detrimento de um ensino superior gratuito.

Na cidade do Juazeiro do Norte o quadro já se torna outro, ou seja, a demanda pela busca de cursos na educação superior no nível de graduação e especialização se deu por via das instituições privadas, em contrapartida, no nível de mestrado e doutorado a demanda foi para as instituições públicas. Cabe dizer que este município é um dos que mais cresce dos três que compõem o bloco e é onde também tem sido instaladas um número maior de instituições privadas de graduação e pós-graduação nos últimos anos.

Contudo, no município de Barbalha praticamente a demanda foi em sua maioria para as instituições privadas sendo que no nível de especialização e doutorado não foi constado nenhuma demanda para as instituições públicas. Um dado preocupante que levanta a hipótese que as políticas públicas de acesso à educação superior não estão respondendo a demanda da população, já que a sociedade deve ter o acesso gratuito e de forma democrática ao ensino superior, direito assegurado pela constituição.

Brito (2014) ressalta que o fenômeno da interiorização do ensino superior relaciona-se com as transformações não somente econômicas, mas de cunho social e espaciais, considerando, ainda, a mobilidade populacional, o fluxo econômico em maneira geral e a maior integração das novas sociabilidades com o território.

Contudo, o processo de interiorização ainda está relacionado com os interesses políticos e a economia local. Nesse contexto Brito (2014) assevera a importância da "qualificação" do trabalho de um município/região, pois abre um maior leque de oportunidades para investimentos e integração econômica. É o que se pode observar diante das três cidades da macrorregião do Cariri, principalmente no que se refere a cidade de Juazeiro do Norte.

A tabela 02 mostra as cidades e as instituições presentes no CRAJUBAR. Nota-se que a cidade de Juazeiro do Norte detém o maior número de instituições de ensino, contudo pela via privada contando com 9 instituições, dentre as quais apenas 4 instituições são públicas. Esse fato pode explicar o número de pessoas graduadas no ensino privado nesse município, dado que a oferta de instituições privadas é nitidamente maior que as públicas, por consequência, enfatiza a concorrência de mercado entre as instituições privadas, fortalecendo a tese da mercantilização da educação no Ensino Superior. 
Tabela 02 - Relação das Instituições de Ensino Superior público e privadas no triângulo CRAJUBAR

\begin{tabular}{|c|c|c|}
\hline \multirow[b]{2}{*}{ Crato } & Pública & $\begin{array}{l}\text { Instituto Federal de Educação, Ciências e Tecnologia do } \\
\text { Ceará - IFCE } \\
\text { Universidade Federal do Cariri - UFCA } \\
\text { Universidade Regional do Cariri -URCA }\end{array}$ \\
\hline & Privada & $\begin{array}{l}\text { Centro Universitário São Camilo } \\
\text { Faculdade Batista do Cariri - FBC } \\
\text { Faculdade Católica do Cariri } \\
\text { Universidade Paulista - UNIP }\end{array}$ \\
\hline \multirow[b]{2}{*}{$\begin{array}{l}\text { Juazeiro do } \\
\text { Norte }\end{array}$} & Pública & $\begin{array}{l}\text { Instituto Federal de Educação, Ciências e Tecnologia do } \\
\text { Ceará - IFCE } \\
\text { Faculdade de Tecnologia Centec - CENTEC } \\
\text { Universidade Federal do Cariri - UFCA } \\
\text { Universidade Regional do Cariri -URCA } \\
\end{array}$ \\
\hline & Privada & $\begin{array}{l}\text { Centro Universitário de Maringá - UNICESUMAR } \\
\text { Centro Universitário Doutor Leão Sampaio - FLS } \\
\text { Faculdade de Juazeiro do Norte - FJN } \\
\text { Faculdade de Medicina Estácio - FMJ } \\
\text { Faculdade Paraiso do Ceará - FAP } \\
\text { Universidade Anhanguera - UNIDERP } \\
\text { Universidade Estágio de Sá - UNESA } \\
\text { Universidade Paulista - UNIP } \\
\text { Universidade Salvador - UNIFACS }\end{array}$ \\
\hline \multirow[b]{2}{*}{ Barbalha } & Pública & $\begin{array}{l}\text { Instituto Federal de Educação, Ciências e Tecnologia do } \\
\text { Ceará - IFCE } \\
\text { Universidade Federal do Cariri - UFCA }\end{array}$ \\
\hline & Privada & $\begin{array}{l}\text { Universidade Luterana - ULBRA } \\
\text { Universidade Pitágoras - UNOPAR }\end{array}$ \\
\hline
\end{tabular}

Fonte: E-MEC.

Brito (2014) evidencia que a região e o local são fatores importantes para a instalação de campi das IES, pois passam a fornecer trabalhadores para as novas dinâmicas locais, suprindo a necessidade dos setores de atendimento à saúde, educação e cultura. É importante destacar, que para a implementação de cursos nas instituições educacionais é realizado um levantamento das necessidades de profissionais das diversas áreas em que uma região demanda. $O$ aumento do número de IES na região do CRAJUBAR demonstra a necessidade que essa região tem por uma mão de obra qualificada. 
No município do Crato novamente o quadro se diferencia de Juazeiro do Norte e de Barbalha, sendo que nesse município são encontradas 3 instituições públicas contra 4 instituições privadas. É notório nos dados do Crato que a presença de instituições públicas em um município amplia a democratização do acesso ao ensino superior, por mais que seja encontrado 4 instituições privadas a população recorre a academia pública. Esse dado confirma a nossa análise anterior de que a população tende a escolher o ensino público em detrimento do ensino privado.

A tabela 02 pode explicar o caso do município de Barbalha, que apesar de fazer parte da macrorregião, sua demanda de acesso ao ensino superior não é atendida. No referido município só é encontrada 1 instituição pública sendo que essa só oferta um curso - Medicina, em contrapartida existe a presença de 2 instituições privadas que oferecem um leque maior de cursos.

Ainda, para demonstrar em dados a necessidade da mão de obra qualificada no Cariri, foi elaborada uma tabela que exemplifica em números a quantidade de docentes, discentes e colaboradores nas principais Instituições de Ensino Superior IES do Crajubar. Ressalta-se que os dados foram colhidos das Comissões Próprias de Avaliação, ou seja das CPA's mais recentes de cada instituição.

Realizada a análise da tabela 3 nota-se a demanda por um corpo docente qualificado já que dentre essas IES o número é de 1.609 docentes, número ainda pouco para atender aos 25.776 discentes. Os dados mostram que a área educacional no Cariri é de fundamental importância para o desenvolvimento regional. Fato que de acordo com a tabela, a geração de empregos foi no total de 2.257 postos somados docentes e colaboradores, notadamente esse número representa o quantitativo das maiores IES do Cariri.

O número de discentes que chega a 25.776 também destaca a demanda existente pela busca do ensino superior e a necessidade de mão de obra qualificada na região. $\mathrm{O}$ que torna de suma importância a continuação de políticas públicas que impulsionem a interiorização do ensino superior. 
Tabela 3 - Número de docentes, discentes e colaboradores das principais IES do CRAJUBAR

\begin{tabular}{|l|l|l|l|}
\hline IES & Docentes & Discentes & Colaboradores \\
\hline FAP & 105 & 2436 & não informado \\
\hline FJN & 112 & 1717 & 56 \\
\hline UNILEÃO & 338 & 6700 & não informado \\
\hline FMJ & 318 & 2070 & 56 \\
\hline UFCA & 163 & 3240 & 277 \\
\hline URCA & 573 & 9613 & 259 \\
\hline
\end{tabular}

Fonte: Comissões Próprias de Avaliação - CPA's. Tabela elaborada pelos autores.

Dentro desta perspectiva de expansão das IES na região do CRAJUBAR, a qualidade do ensino nessas diversas instituições torna-se indispensável para diagnosticar o crescimento da oferta de universidades se dá concomitantemente a manutenção da qualidade de ensino e consequentemente dos profissionais formados. Nesse sentido o Exame Nacional de Desempenho dos Estudantes (ENADE) é o principal indicador da qualidade no Ensino Superior.

Sob essa égide, no Município do Crato, onde o maior número de alunos está distribuído em instituições públicas, a Universidade Regional do Cariri - URCA exerce um papel de destaque abrigando a maior diversidade de cursos, nos quais suas notas variam de 1 a 4 no conceito ENADE. Dentre eles, apenas 1 apresenta a nota mínima e dois deles a pontuação 4 , apresentando aproximadamente $73 \%$ com notas 2 e 3 evidenciando um desemprenho mediano, no entanto, consoante com o desenvolvimento regional.

Entretanto, no Município de Juazeiro do Norte, o protagonismo se concentra dentre 2 instituições, sendo elas a Universidade Federal do Cariri - UFCA no ensino público e o Centro Universitário Leão Sampaio - FLS no privado ambos com $80 \%$ dos cursos tendo notas entre 3 e 4, sendo a FLS que apresenta a maior diversidade de 
cursos, no entanto a UFCA concentra notas maiores em seus cursos. A URCA também tem campus na cidade, porém seu desempenho é inferior as outras instituições destacadas, com cursos classificados com notas 1 e 2.

Na região há dois cursos de medicina, na Faculdade de Medicina de Juazeiro - FMJ, instituição privada do Grupo Estácio, que apresenta nota 3 localizada em Juazeiro do Norte e na UFCA em Barbalha com nota 4.

Essa flexibilização de aberturas de instituições privadas se deu por questões ideológicas colocadas em práticas a partir da década de 1990, com o decreto 2306/97 que autorizou a "diversificação" da educação superior, contribuindo significativamente para a expansão do setor privado (BRITO, 2014).

Já no que é relativo à questão da descentralização das instituições de ensino superior, uma resposta ao quadro de Juazeiro do Norte, seria a emergência de novos polos universitários, que modificou a mobilidade entre os municípios com as suas respectivas capitais. O que possibilita caminhos para um novo contexto econômico que possa contribuir com a diminuição da desigualdade social. Ainda nesse viés, suscita a análise de um novo desenho de desenvolvimento regional que visa um perfil de seletividade migratória de fatores de atração comercial (FUSCO; OJIMA, 2017).

\section{CONSIDERAÇÕES FINAIS}

Com efeito, o presente trabalho apresentou um panorama dos caminhos que as políticas públicas percorreram e que contribuíram para interiorização do ensino superior no Estado do Ceará, mais particularmente na macrorregião do Cariri, região na qual vem se observando um acentuado crescimento econômico em decorrência da migração de grandes polos industriais. De acordo com as análises, é notório que as políticas tomadas favoreceram à mercantilização da educação, quando flexibilizou a abertura de graduações e pós-graduações pela via do setor privado.

Ressalta-se que as políticas públicas devem estar voltadas para o fortalecimento do tripé universitário no ensino público. Entende-se que essas políticas devem atender a toda a população e não somente a uma parcela dela. Fato que pode ser observado em Barbalha, que apesar de fazer parte da macrorregião do Cariri, sofre às duras penas com sua menor arrecadação na economia local. 
Destaca-se ainda para a importância das potencialidades do desenvolvimento regional sustentável através das potencialidades do Geoturismo, característica ímpar da região na qual pode se observar a relevância da pesquisa nos geoparques. Caso bastante explorado em pesquisas no Mestrado em Desenvolvimento Regional Sustentável da UFCA.

Dessa forma é bastante salutar que as políticas públicas atendam as necessidades, assim como arrecadação e o fortalecimento do desenvolvimento regional nos municípios mais carentes no que diz respeito à prestação de serviços educacionais de qualidade de nível superior.

Contudo, a questão da democratização do ensino superior foi sentida na macrorregião do cariri, porém não foi pela via pública o que nos faz refletir no favorecimento das instituições privadas de ensino superior. Destaca-se que a democratização e interiorização na Região Nordeste é de suma importância para o desenvolvimento regional e nacional, além de beneficiar as regiões contempladas com as IES, melhorando de forma substancial os índices econômicos e sociais, formando novos polos universitários e descentralizando as oportunidades de acesso à educação que antes só eram encontradas nas capitais.

De certa forma observa-se que análises realizadas no decorrer da pesquisa vem demonstrar o contraste que foi criado entre o discurso de democratização da Educação Superior e o que foi de fato efetivado na prática. A partir dos resultados da parceria público-privada nota-se a incapacidade de garantir educação pública a nível de educação superior gratuita a toda à população. O que se sugere uma melhor análise e reformulação das políticas públicas aplicadas, principalmente no contexto da realidade em estudo.

Para efeito de conclusão, a expansão e a interiorização do ensino superior no Cariri foram importantes, todavia ressalta-se que deve ocorrer uma expansão do ensino público de forma que as vagas contemplem o contingente de egressos no Ensino Superior, tornando-o mais democrático e acessível a classe trabalhadora. Nesse sentido, sugere-se que novas análises sejam realizadas acerca das políticas públicas já implementadas nesta macrorregião, com o intuito de potencializar ainda mais o seu crescimento e sustentabilidade econômicas, assim como a investigação dos discursos políticos e sua efetiva implementação. 


\section{REVISTA CEENGIAE SUSTENTABBLLDADE \\ ISSN 2447-4606 v.5, n. 1, jan-jun, 2019}

\section{REFERÊNCIAS}

BRASIL, Ministério da Educação. Disponível em: http://emec.mec.gov.br/. Acesso em: nov. 2018.

BRITO, Leonardo Chagas de. A importância dos estudos sobre interiorização da universidade e reestruturação territorial. Espaço e Economia. Revista brasileira de geografia econômica, n. 4, 2014.

CENSO DEMOGRÁFICO 2010. Características da população e dos domicílios: resultados do universo. Rio de Janeiro: IBGE, 2011. Disponível em: http://www. ibge.gov.br/home/estatistica/populacao/censo2010/caracteristicas_da_populaca/ resultados_do_universo.pdf. Acesso em: nov. 2018.

CHAUÍ, Marilena. (1999). A universidade operacional. Folha de S. Paulo, São Paulo, Domingo, 09 de maio de 1999. Mais! 5-3 Brasil 500 D.C.

FACULDADE DE MEDICINA - FMJ. Comissão Própria de Avaliação CPA. Disponível em: http://portal.estacio.br/unidades/faculdade-de-medicinaest\%C3\%A1cio-de-juazeiro-do-norte/. Acesso em: Jul.2019.

FACULDADE PARAISO - FAPCE. Comissão Própria de Avaliação - CPA.

Disponível em: https://www.fapce.edu.br/. Acesso em: Jul. 2019.

FUSCO, Wilson; OJIMA, Ricardo. Nordeste do Brasil: interiorização do ensino superior e mobilidade pendular. Anais, p. 1-8, 2017.

INSTITUTO Nacional de Estudos e Pesquisas Educacionais Anísio Teixeira. Disponível em: http://www.inep.gov.br/. Acesso em: nov. 2018.

INSTITUTO Brasileiro de Geografia e Estatística. Disponível em: https://www.ibge. gov.br/. Acesso em: nov. 2018.

KRAWCZYK, Nora Rut et al. Políticas de regulação e mercantilização da educação: 
socialização para uma nova cidadania. Educação \& Sociedade, v. 26, n. 92, p. 799819, 2005.

LEHER, Roberto. Luta de classes e mercantilização da educação brasileira. In: III International Conference Strikes and Social Conflicts: combined historical approaches to conflict. Proceedings. CEFID- UAB,, 2016. p. 959-971.

LIMA, Katia Regina R.; PRADO, Francisca H. Saboia; NOVAES, Marcos Adriano. Estado, Políticas Públicas, Contrarreforma e acesso à Educação Superior no governo Lula da Silva. JORNADA INTERNACIONAL DE POLÍTICAS PÚBLICAS, v. 5 , p. 1-10, 2011.

MANCEBO, Deise; JÚNIOR, João dos Reis Silva; SCHUGURENSKY, Daniel. A educação superior no Brasil diante da mundialização do capital. Educação em Revista, v. 32, n. 4, 2016.

SAMPAIO, Carlos Magno Augusto; DOS SANTOS, Maria do Socorro; MESQUIDA, Peri. Do conceito de educação à educação no neoliberalismo. Revista Diálogo Educacional, v. 3, n. 7, p. 165-178, 2002.

SGUISSARDI, Valdemar. A universidade neoprofissional, heterônoma e competitiva. Universidade: políticas, avaliação e trabalho docente. São Paulo: Cortez, p. 33-52, 2004.

UNIVERSIDADE FEDERAL DO CARIRI - UFCA. Comissão Própria de Avaliação - CPA. Disponível em: www.ufca.edu.br/. Acesso em: Jul. 2019.

UNIVERSIDADE REGIONAL DO CARIRI - URCA. Comissão Própria de Avaliação - CPA. Disponível em: www.urca.br/novo/portal/. Acesso em: Jul. 2019. 